\title{
Wechsler Memory Scale performance and its relationship to brain damage after severe closed head injury
}

\author{
D. N. B R O O K S \\ From the University Department of Psychological Medicine, \\ Southern General Hospital, Glasgow
}

SYNOPSIS Eighty-two patients with severe head injury were tested on the Wechsler Memory Scale and compared with 34 normal subjects. Head injured patients had severe memory difficulties, particularly on Logical Memory and Associate Learning. Severity of head injury (posttraumatic amnesia duration) was related to poor memory, as was increasing age, but both persisting neurological signs, including dysphasia, and skull fracture were not.

Despite the large number of severely head injured patients admitted to hospital each year, we still have a little experimental information about the cognitive consequences of such injuries. Many researchers have commented on memory deficits as a consistent feature after head injury (Williams and Zangwill, 1952; Fahy et al., 1967; Hpay, 1971; Russell, 1971) but few studies have examined later recovery of memory in relation to severity of brain damage. Tooth (1947) showed a negative association between duration of post-traumatic amnesia (PTA) and severity of cognitive deficit, although he found no relationship between deficit and either persisting neurological signs or skull fracture. Kløve and Cleeland (1972) found patients with prolonged coma worse on memory tests than those with shorter coma and Brooks (1972) suggested that severity of diffuse brain damage (assessed by PTA duration) was an important factor determining later recovery of memory. In subsequent papers Brooks $(1974 \mathrm{a}, \mathrm{b})$ found no association between memory and either persisting neurological signs or skull fracture.

The current study extended earlier work by the author by studying memory deficits in a

(Accepted 9 February 1976.) large sample of 82 patients who had suffered a severe closed head injury. The aims of the research were twofold: (1) to determine the incidence and severity of memory problems in the group of head injured patients as a whole; (2) to examine the importance of the following factors in memory recovery-severity of diffuse brain damage assessed by duration of PTA; severity of focal brain damage assessed by persisting focal neurological signs; the presence of skull fracture; the time after injury; and the age of the patient.

\section{METHODS}

PATIENTS STUDIED The head injured sample comprised 82 patients (nine female) who had suffered closed head injury resulting in PTA (defined as the interval between injury and regaining continuous day-to-day memory) of at least two days. The 82 patients consisted of two subgroups: (1) 30 consecutive unselected neurosurgical cases, and (2) 52 patients referred to the author for examination of cognitive recovery after head injury.

The two subgroups did not differ significantly on any of the memory tests and were therefore treated as a single uniform group. The means and ranges of PTA, age, and time after injury at which the patients were tested are shown in Table 1. 
T A B L E 1

CHARACTERISTICS OF HEAD INJURY GROUP

\begin{tabular}{|c|c|c|c|c|c|c|}
\hline & \multicolumn{5}{|c|}{$P T A($ days $)$} & \multirow[b]{2}{*}{ Mean 40.3} \\
\hline & \multicolumn{2}{|c|}{14 or below } & \multirow{2}{*}{$\frac{15-28}{22}$} & \multicolumn{2}{|c|}{ Over 28} & \\
\hline \multirow[t]{3}{*}{ Cases (no.) } & 28 & & & & 32 & SD $\quad 52.9$ \\
\hline & \multicolumn{5}{|c|}{ Age $(y r)$} & \\
\hline & $16-2$ & & $30-45$ & & $5-60$ & Mean 31.7 \\
\hline \multirow[t]{3}{*}{ Cases (no.) } & 41 & & 25 & & 16 & SD 13.2 \\
\hline & \multicolumn{5}{|c|}{ Time (months) } & \\
\hline & $0-3$ & $4-6$ & $7-12$ & $13-24$ & Over 24 & Mean 13.1 \\
\hline Cases (no.) & 20 & 15 & 14 & 19 & 14 & SD 13.3 \\
\hline
\end{tabular}

No patient was seen until out of hospital, fully orientated, and clearly out of PTA. This was to ensure that only late cognitive deficits were studied.

CONTROLS The head injured patients were compared with 34 orthopaedic patients suffering primarily fractures of the lower limbs. This group was chosen because, like the head injured group, it consisted of patients who had suffered trauma resulting in hospital treatment. No member of the control group suffered a head injury.

Head injured and control patients were well matched on age and on years of full-time education received (age: head injured; $31.7 \pm 13.2$ years, control subjects $30.8 \pm 11.8$ years; $t=0.3$ NS. Education: head injured; $15.6 \pm 1.4$ years, control subjects $15.4 \pm 1.3$ years; $t=0.2$ NS).

PROCEDURE Memory was tested using the Wechsler Memory Scale (Wechsler, 1945), a widely used clinical scale comprising a number of subtests. The scale is far from ideal, in that memory functions underlying performance on the test are not clear and the Memory Quotient is an unweighted summary of very different subtests. However, few clinical batteries of memory tests are available and it was felt that as a preliminary screening tool its individual subtests could reasonably be used, but the Memory Quotient was discarded.

The scale includes the following subtests:

1. Information (I): six questions on general knowledge.

2. Orientation (O): five questions for orientation in time and place.

3. Mental Control (MC): the ability to repeat sequences such as the alphabet.
4. Logical Memory (LM): immediate repetition of short stories presented auditorily. As a variation from conventional administration, patients were asked without warning to recall the story again one hour later. The test may, therefore, be considered to consist of two trials.

5. Digits Forwards (DF), Digits Reversed (DR): the conventional digit span tests.

6. Visual Reproduction (VR): reproduction by drawing of three simple designs, each presented individually for 10 seconds.

7. Associate Learning (AL): the patient is given three trials to learn 10 pairs of words; six are obvious (up-down), and four difficult (cabbage-pen). The procedure was modified by giving a further trial without warning after one hour, so the test may be considered as four trialsthree learning trials and one retention trial.

In the present study, Information and Orientation were combined to make one score ( $\mathrm{I}$ and $\mathrm{O}$ ), and Mental Control was examined in terms of mean number of errors (MCE) and mean completion time (MCT).

Patients were seen once only for the purpose of this study and the times after injury at which they were seen are indicated in Table I.

METHODOLOGY The first aim of the study was to compare head injured and control patients and this was done by use of $t$ tests for the following memory tests-Information plus Orientation (I and O), Mental Control Errors (MCE), Mental Control Time (MCT), Digits Forwards (DF), Digits Reversed (DR), and Visual Reproduction (VR). The results of these tests will therefore be presented together. The remaining two tests, Logical Memory (LM) and Associate Learning (AL) each comprised more than one trial, and these were analysed by split plot factorial analysis of variance with least squares solution for unequal N's (Kirk, 1968) using patient groups as the between subjects factor, and learning trials as the within subjects factor. This method also enables one to calculate a Groups $\times$ Trials interaction which, if significant, would indicate a difference in the learning or retention curves.

The second aim of the study was to examine various prognostic factors in memory recovery after closed head injury and for this purpose the head injury group was divided into two or three subgroups on the relevant variable. The subtests not involving more than one trial were then compared across the subgroups using one way analysis of variance, and the remaining two tests (LF and AL) were compared using split plot analysis of variance. It was also of interest to 
T A B LE 2

SCORES OF HEAD INJURED AND CONTROL PATIENTS ON GROUP I MEASURES

\begin{tabular}{|c|c|c|c|c|c|c|}
\hline \multirow[b]{2}{*}{ Test } & \multicolumn{2}{|c|}{ Head injury } & \multicolumn{2}{|c|}{ Controls } & \multirow[b]{2}{*}{$t$} & \multirow[b]{2}{*}{ Sig. } \\
\hline & $M$ & $S D$ & $M$ & $S D$ & & \\
\hline Information and orientation & 9.4 & 1.5 & 10.1 & 0.9 & 2.7 & $\mathrm{P}<0.01$ \\
\hline Mental control (errors) & 0.6 & 0.9 & 0.8 & 1.2 & 1.3 & NS \\
\hline Mental control (time) & 12.8 & 11.1 & 8.0 & 2.5 & 4.0 & $P<0.01$ \\
\hline Digits forwards & 6.3 & 1.1 & 6.7 & 1.0 & 1.9 & NS \\
\hline Digits reversed & 4.2 & 1.3 & 5.2 & 1.1 & 3.8 & $P<0.01$ \\
\hline Visual reproduction & 7.8 & 3.3 & 9.3 & 2.1 & 2.4 & $\mathrm{P}<0.05$ \\
\hline
\end{tabular}

compare each of the head injury subgroups with the controls, so controls were included in the analyses.

\section{RESULTS}

COMPARISON OF HEAD INJURED AND CONTROL PATIENTS The results are shown in Tables 2, 3 , and 4.

On six of the eight memory tests, head injured patients performed significantly worse than controls. The tests on which the two groups did not differ significantly were MCE (but not on Time) and DF. MC relies on repetition of overlearned simple sequences and, although head injured patients were slower, they were not less accurate. Similarly, DF is a simple span task that seems resistant to the types of brain damage resulting in memory disturbance (Talland, 1965; Baddeley and Warrington, 1970).

On LM head injured patients were significantly worse at immediate and delayed recall. On AL head injured patients were significantly poorer, and there was a significant interaction

TA B L E 3

SCORES OF HEAD INJURY AND CONTROL PATIENTS ON LOGICAL MEMORY

\begin{tabular}{|c|c|c|c|c|}
\hline \multirow[b]{2}{*}{ Test } & \multicolumn{2}{|c|}{ Head injury } & \multicolumn{2}{|c|}{ Controls } \\
\hline & $M$ & $S D$ & $M$ & $S D$ \\
\hline $\begin{array}{l}\text { Immediate recall } \\
\text { Delayed recall }\end{array}$ & 8.2 & 3.3 & $\begin{array}{r}12.3 \\
0.9\end{array}$ & 2.8 \\
\hline
\end{tabular}

F: groups 43.3 (df 1.114) $P<0.01$

$F$ : trials $286.6(\mathrm{df} 1,114) \mathrm{P}<0.01$.

$\mathrm{F}: \mathrm{G} \times \mathrm{T} 0.2(\mathrm{df} 1.114) \mathrm{NS}$. suggesting a different learning curve in the two groups. Plotting the curve showed that the rate of learning in the head injured groups was lower than in controls, with the group difference increasing at each trial. Furthermore, the loss due to forgetting appeared greater in the head injury group, although on tests for simple main effects head injured patients were significantly worse $(\mathrm{P}<0.01)$ at all trials.

FACTORS OF POTENTIAL PROGNOSTIC SIGNIFICANCE The second aim of the study was to examine various factors (PTA duration, neurological signs, skull fracture, time, and age) within the head injured group which may be associated with a poor memory. Although the factors were probably not independent, with interactions possible, for the purposes of statistical analysis each was analysed independently. Thirty six patients showed focal neurological signs alone ('severe' in seven patients and 'moderate' in 20) and, of the 36, seven showed dysphasia and 21 had a skull

\section{T A B L E 4}

SCORES OF HEAD INJURY AND CONTROL PATIENTS ON ASSOCIATE LEARNING

\begin{tabular}{cccccc}
\hline & \multicolumn{2}{c}{ Head injury } & & \multicolumn{2}{c}{ Controls } \\
\cline { 2 - 3 } \cline { 5 - 6 } Trial & $M$ & $S D$ & & $M$ & $S D$ \\
\hline 1 & 5.5 & 2.2 & & 7.8 & 2.5 \\
2 & 7.2 & 3.1 & & 11.7 & 2.0 \\
3 & 9.7 & 3.5 & & 12.7 & 1.8 \\
4 & 8.0 & 3.5 & & 12.0 & 2.6 \\
\hline
\end{tabular}

F: groups 38.7 (df 1.342) $\mathrm{P}<0.01$.

F: trials 125.5 (df 3.342) $P<0.01$.

$F: G \times T \quad 3.1($ df, 3,342) $P<0.05$. 
fracture. Mean PTA for patients with moderate or severe neurological signs was 60 days and for the remaining patients it was 43 days. The large difference in PTA was due to the presence of eight patients in the 27 with moderate-severe signs who showed very long PTAs of 90 days or more.

a. Severity of brain damage assessed by duration of PTA Russell (1971) classified severity of concussion in terms of PTA duration, describing a PTA of one to seven days as 'severe concussion' and one of one week or more as 'very severe concussion'. Above a PTA of one week, Russell did not distinguish between lengths of PTA, and clinical experience shows that reliability of PTA assessment decreases with increasing PTA length. Despite this, it seemed worth investigating the association between longer durations of PTA and memory, and the group of 82 patients was subdivided into four subgroups as follows: (1) PTA seven days or less (14 patients); (2) PTA eight to 14 days (14 patients); (3) PTA 15 to 28 days (22 patients); (4) PTA 29 days or more (32 patients).

It was hoped that within these divisions PTA could be assessed sufficiently accurately, and that the divisions might be of clinical significance.

The four subgroups and controls were compared on the memory tests (Tables 5, 6, and 7).

In the first group of tests, a significant $F$ ratio was found with $I$ and $O, M C T, D R$ and
VR. On I and $O$, the raw scores did decrease consistently with increasing PTA, but on Scheffé tests the only significant difference was between severity subgroup 4 (most severely damaged) and controls. The three less severely injured groups did not therefore differ from the controls. On both MCT and VR, each of the head injured groups was significantly worse than controls but no within head injury comparison was significant. On these there was some evidence of a severity effect for $\mathrm{I}$ and $\mathrm{O}$ but not for the remaining tests.

For LM (Table 6), raw scores diminished with increasing PTA up to a PTA of four weeks, and there were significant Groups and Trials $F$ ratios. Scheffe tests showed that the three more severely damaged groups each differed significantly from controls at both trials, but the least severely damaged group did not Patients in severity subgroup 1 (least severelyo damaged) were significantly better than those in either group 3 or group 4. There was, there fore, a significant association between LM and length of PTA with some kind of threshold above a PTA of about four weeks, after which duration of PTA was less important.

For AL (Table 7) Groups and Trials F ratios were both significant, and Scheffé tests showed that for trials 2,3 , and 4 , the three most severely damaged groups, each differed significantly from controls, with the least severely damaged group performing at the same level as controls. Also, the least severe group was

T A B L E 5

PTA DURATION AND MEMORY SCORE ON GROUP I TESTS

\begin{tabular}{|c|c|c|c|c|c|c|c|c|c|c|c|c|}
\hline \multirow{3}{*}{ PTA (days): } & \multicolumn{8}{|c|}{ PTA group } & & & & \\
\hline & \multicolumn{2}{|c|}{$\underset{1}{1}$} & \multicolumn{2}{|c|}{$\underset{8-14}{I I}$} & \multicolumn{2}{|c|}{$\underset{15-28}{I I I}$} & \multicolumn{2}{|c|}{$\begin{array}{r}I V \\
>29\end{array}$} & \multicolumn{2}{|c|}{ Controls } & \multicolumn{2}{|c|}{$\begin{array}{c}F \\
(d f 4,111) \text { Sig }\end{array}$} \\
\hline & $M$ & $S D$ & $M$ & $S D$ & $M$ & $S D$ & $M$ & $S D$ & $M$ & $S D$ & & \\
\hline \multicolumn{6}{|l|}{ Information and } & 1.5 & 8.9 & 2.0 & 10.1 & 0.9 & 2.6 & $P<0.05$ \\
\hline $\begin{array}{l}\text { Mental Control } \\
\text { (Errors) } \\
\text { Mental Control }\end{array}$ & 0.6 & 0.8 & 0.6 & 0.8 & 0.6 & 1.0 & 0.5 & 0.8 & 0.8 & 1.2 & 0.5 & NS \\
\hline (Time) & 16.4 & 15.0 & 17.8 & 14.2 & 14.1 & 10.4 & 14.8 & 7.9 & 8.0 & 2.5 & 4.0 & $\mathrm{P}<0.01$ \\
\hline Digits Forwards & 6.3 & 1.7 & 6.2 & 1.2 & 6.2 & 1.0 & 6.3 & 1.2 & 6.7 & 1.0 & 1.0 & NS \\
\hline Digits Reversed & 4.6 & 1.2 & 4.2 & 1.2 & 3.9 & 1.5 & 4.3 & 1.3 & 5.2 & 1.1 & 4.3 & $P<0.01$ \\
\hline Visual Reproduction & 8.9 & 3.8 & 7.0 & 3.9 & 7.4 & 3.0 & 8.2 & 2.5 & 9.3 & 2.1 & 2.4 & $P=0.05$ \\
\hline
\end{tabular}


T A B LE 6

PTA DURATION AND SCORE ON LOGICAL MEMORY

\begin{tabular}{|c|c|c|c|c|c|c|c|c|c|c|}
\hline \multirow{3}{*}{ PTA (davs): } & \multicolumn{8}{|c|}{ PTA group } & & \\
\hline & \multicolumn{2}{|c|}{$\begin{array}{l}I \\
\leqslant 7\end{array}$} & \multicolumn{2}{|c|}{$\begin{array}{c}I I \\
8-14\end{array}$} & \multicolumn{2}{|c|}{$\begin{array}{c}I I I \\
15-28\end{array}$} & \multicolumn{2}{|c|}{$\begin{array}{l}I V \\
\geqslant 29\end{array}$} & \multicolumn{2}{|c|}{ Controls } \\
\hline & $M$ & $S D$ & $M$ & $S D$ & $M$ & $S D$ & $M$ & $S D$ & $M$ & $S D$ \\
\hline Immediate Recall & 10.3 & 4.3 & 8.8 & 3.4 & 7.4 & 2.7 & 7.5 & 2.9 & 12.3 & 2.8 \\
\hline Delayed Recall & 7.6 & 3.3 & 6.7 & 3.7 & 4.6 & 2.7 & 4.8 & 3.3 & 9.9 & 2.9 \\
\hline
\end{tabular}

F: groups $17.8(\mathrm{df} 4,111) \mathrm{P}<0.01$.

F: trials $82.5(\mathrm{df} 1,111) \mathrm{P}<0.01$.

$\mathrm{F}: \mathrm{G} \times \mathrm{T} \quad 0.2(\mathrm{df} 4,111) \mathrm{NS}$.

TA B LE 7

PTA DURATION AND SCORE ON ASSOCIATE LEARNING

\begin{tabular}{|c|c|c|c|c|c|c|c|c|c|c|}
\hline \multirow{3}{*}{$\begin{array}{c}\text { PTA (days): } \\
\text { Trial }\end{array}$} & - & —. & $\ldots$ & $P T$ & 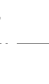 & & \multicolumn{2}{|c|}{$I V$} & \multicolumn{2}{|c|}{ Controls } \\
\hline & \multicolumn{2}{|c|}{$\leqslant 7$} & \multicolumn{2}{|c|}{$8-15$} & \multicolumn{2}{|c|}{$16-28$} & \multicolumn{2}{|c|}{$\geqslant 29$} & & \\
\hline & $M$ & $S D$ & $M$ & $S D$ & $M$ & $S D$ & $M$ & $S D$ & $M$ & $S D$ \\
\hline 1 & 6.3 & 2.7 & 5.3 & 1.6 & 6.0 & 2.3 & 4.8 & 2.3 & 7.8 & 2.5 \\
\hline 2 & 10.4 & 3.0 & 8.4 & 2.9 & 8.9 & 2.8 & 7.4 & 3.3 & 11.7 & 2.0 \\
\hline 3 & 11.7 & 2.8 & 9.4 & 3.5 & 9.7 & 3.7 & 8.6 & 3.8 & 12.7 & 1.8 \\
\hline 4 & 10.6 & 3.0 & 8.0 & 4.0 & 7.9 & 2.8 & 7.0 & 3.4 & 12.0 & 2.6 \\
\hline
\end{tabular}

$\begin{array}{lll}F: \text { groups } & 14.4(\mathrm{df} 4,333) & P<0.01 \\ \mathrm{~F}: \text { trials } & 91.7(\mathrm{df} 3,333) & \mathrm{P}<0.01\end{array}$

$\mathrm{F}: \mathrm{G} \times \mathrm{T} \quad 1.3(\mathrm{df} 12,333) \mathrm{NS}$.

significantly better than the most severe group. On trial 1 the only significant difference was between group 4 (most severe) and controls.

In a previous study, Brooks (1972) had reported an interaction between PTA duration and age in that correlations between PTA and memory were higher in older patients (aged 30 years or over) than in those aged less than 30 years. Those correlations were based on rather small numbers, and a replication was attempted by computing rank order correlations between memory and PTA in the 42 younger patients and in the 40 older patients for LM (Immediate Recall) and for AL Trial 1 (Table 8).

The results are, if anything, opposite to those reported previously and do not support the sugggestion that in older patients the memory/PTA association is greater than in younger patients. The previous finding must, therefore, be suspect, and may be an artefact due to the use of small groups.

b. Severity of brain damage in terms of persisting focal neurological signs. Patients were examined by a neurosurgeon or neurologist either at memory testing or ideally within six weeks of testing. In 10 patients this was not possible, and for those patients the last reported neurological examination appearing in their case sheet was used. This method, crude

\section{TA B LE 8}

RANK CORRELATION COEFFICIENTS BETWEEN MEMORY SCORE AND PTA IN 'YOUNG' AND 'OLD' HEAD INJURED PATIENTS

\begin{tabular}{lcc}
\hline \multicolumn{1}{c}{ Test } & Young & Old \\
\hline Logical Memory & -0.35 & -0.27 \\
Associate Memory & -0.52 & -0.13 \\
\hline
\end{tabular}


though it is, should not lead to too great an inaccuracy, as patients were classified into only three grades as shown below:

Grade 155 patients showing minimal or no focal neurological signs. No impairment in day-to-day life due to the presence of focal signs. 'Good recovery'.

Grade 221 patients with moderate focal neurological signs causing some impairment in day-to-day life, but not rendering the patient completely dependent on others. 'Moderate recovery'.

Grade 3 six patients with marked or severe focal neurological signs leading to severe impairment of day-to-day life so that the patient could not live a completely independent existence. 'Bad recovery'.

The 55 patients in group 1 were compared with the 27 patients in groups 2 and 3 combined, and with controls. The only test on which a significant overall $\mathrm{F}$ ratio was not found was MCE, although $F$ ratios for $I$ and $\mathrm{O}$, for $\mathrm{DF}$, and for VR only just reached significance at $P=0.05$. Scheffé tests show that the two head injury subgroups did not differ significantly on any of the tests with the single exception of trial 3 on $\mathrm{AL}$, on which patients with signs were significantly $(\mathrm{P}<0.05)$ poorer than those without. On all other tests both head injury subgroups were significantly worse than the controls.

c. Skull fracture The presence of a skull fracture is a rather contentious prognostic sign. Tooth (1947) and Ruesch and Moore (1943) found that skull fracture was associated with a greater degree of disability, but Denny-Brown (1945) and Kløve and Cleeland (1972) did not find such an association. One possible reason for this discrepancy is that Tooth and Ruesch studied mild injuries, whereas Kløve and Cleeland studied more severe injuries. However, Denny-Brown's patients had suffered mild injuries also. In the present study the 41 patients with skull fracture of any type were compared with those without. The $F$ ratios were significant on all tests except MCE, but on Scheffé tests, with the single exception of DR, there was no differences on any memory test between patients with fracture and those without. On DF, the patients with fracture were slightly but significantly poorer (mean score 6.0) than those with no fracture (mean score 6.5).

d. Length of time after injury As patients were seen at widely differing times after injury, this afforded an opportunity to study the time course of recovery of memory. Ideally, one would use a test-retest method with retested controls to do this, but the lack of sufficient equivalent alternative forms of the tests, the high drop-out rate of patients in such a consecutive study currently being conducted, and the difficulty in obtaining sufficient retested controls, made the following methodology necessary. Patients were subdivided into those tested during the following time blocks:

1. 'Early' 14 patients tested one to four months after injury.

2. 'Medium' 12 patients tested from five to 12 months after injury.

3. 'Late' 12 patients tested 13 or more months after injury.

The large size of the total head injury group allowed the patients to be closely matched within each time subgroup, and patients were carefully matched in terms of age and PTA:

Age in years group I, 30.8; group II, 28.7; group III, $33.3 \quad \mathrm{~F}=0.8 \mathrm{NS}$.

PTA in days group I, 14.9; group II, 15.7; group III, $15.5 \quad \mathrm{~F}=0.2 \mathrm{NS}$.

The three 'time' groups of patients and controls were compared on each memory test. $F$ ratios were significant for MCT, DR, VR, LM, and AL. On DR and VR, only the 'earliest' patients were significantly worse than controls, with no significant difference between the two later groups and controls. On MCT, LM, and AL, each head injured group differed significantly from controls (at all trials for $\mathrm{LM}$ and $\mathrm{AI}$ ), but there were no within head injury group differences. On AL, raw scores tended to increase with the time at which the patient was tested, but this was not a significant effect.

The data were examined further by using all 82 head injured patients and calculating product moment correlations between memory 
score and the time at which the patient was tested. None of the coefficients reached statistical significance. This method is a little crude, as the recovery function over the time scale considered here is certainly not uniform, being rapid initially and slower thereafter. The correlations were repeated in patients tested six months or less after injury who might be expected to be still in the phase of rapid recovery but no significant coefficients were found. It should be borne in mind that reducing the numbers in this way would attenuate any correlation that may be present.

e. Age of patient at injury Age was considered important, not only because with increasing age ease and rapidity of learning diminish, but because ability to withstand and to recover from trauma reduces with increasing age (Carlsson et al., 1968).

The age and memory association was studied by dividing head injured patients into 42 'young' aged 30 years or less and 40 'old' patients aged over 30 years. The two age groups and controls were compared giving significant $F$ ratios on IO, MCT, DR, VR, LM, and AL. On IO, DR, and LM (both trials) both head injury subgroups were significantly worse than controls, but did not differ significantly between themselves. On MCT, only older patients were significantly worse than controls, but they did not differ significantly from younger patients. On $\mathrm{AL}$ both head injury groups were significantly poorer than controls, but younger patients were significantly better than older patients on trials 2,3 , and 4 .

\section{DISCUSSION}

The results here support previous findings of marked memory deficit in patients with severe closed head injury many months after injury. Not all the memory tests were equally affected and on Digits Forwards, a simple span test, and on errors on Mental Control, a simple repetition test, there were no consistent differences between head injured and control patients.

The remaining single trial tasks showed a range of difficulty for head injured patients, the most difficult test being Mental Control (Time) followed by Digits Reversed, Information and Orientation, and Visual Reproduction. The severe difficulty that head injured patients found on Mental Control (Time) is no surprise, in view of complaints of 'slowness' made by many head injured patients. Similarly, the poor performance on Digits Reversed is easy to understand clinically. This is a difficult task in which the patient must hold information while attending to new incoming information. Head injured patients of ten complain of attentional difficulties-for instance, in conversation, where they are unable to concentrate adequately on more than one person speaking.

The two tests with the long-term (one hour) retention component proved very difficult for head injured patients. On Logical Memory head injured patients were significantly poorer at immediate and delayed recall, although their rate of forgetting was not significantly greater than controls. On Associate Learning, head injured patients were significantly worse at all levels of the task, and their rate of learning was significantly lower. The simple comparisons between head injured and control patients suggest that in order to reveal deficits shown across the whole range of head injured patients, tests with a prolonged learning component and with a retention component are the most useful.

A number of prognostic variables were investigated, but few proved to be of major significance. Duration of PTA had some influence on the simpler memory tasks; and on the two learning tasks (Logical Memory and Associate Learning) there was clear evidence of negative association with PTA.

The presence of focal neurological signs was not of significance except possibly on Information and Orientation and on Visual Reproduction. Neither the presence (nor the site) of a skull fracture appeared to be of importance. Both focal signs and skull fracture may be considered to be assessing localized brain damage, whereas PTA assesses diffuse damage and the presence of focal brain damage is not therefore of importance in the genesis of memory defect after severe head injury, although the severity of diffuse brain 
damage is important. The lack of significance of focal damage in this group of severely damaged patients is not surprising, as any focal sign must be interpreted against a background of severe diffuse damage, indicated by PTA. PTA showed some evidence of a threshold association with memory dysfunction in that patients with PTA of one week or less were much less affected on memory than other patients.

The time after injury when the patient was tested was not very important in this study, although there was an indication that patients tested at the earliest interval (less than four months after injury) did perform more poorly than those seen later. This suggests that recovery of memory (often to a low and deteriorated level) may take place very early after injury, and this has important implications for clinical rehabilitation of head injured patients. Although the methodology chosen in the study was not ideal, relying on small matched groups of patients seen at different time intervals, the suggestion of rapid early recovery to an early low level agrees with previous findings for physical recovery (Bond, 1975) and for memory (Brooks, 1972, 1974a, b; Levin et al., 1976), but does not accord with Wechsler Intelligence Scale scores in a different sample of patients treated in the same institute (Mandleberg and Brooks, 1975). It is quite possible that intelligence and memory recover at very different rates (intelligence being a much more global and multifactorial function) and that alone could explain the discrepancy. This will be supported by the finding in the present study that, using Raven's tests, the IQ vs memory correlations were all small and insignificant.

Age proved to be important in the more difficult memory tasks. On Associate Learning, the most difficult task, older patients were significantly worse than younger patients.

In conclusion, there are four main points arising from this research: (1) severe head injury has marked late effect on memory and learning; (2) PTA representing diffuse brain damage is an important prognostic sign; (3) focal brain damage is of relatively little significance in the genesis of memory deficits in this group of patients; (4) recovery of memory to a stable but low level may take place early, possibly within the first six months after injury.

\section{REFERENCES}

Baddeley, A. D., and Warrington, E. K. (1970). Amnesia and the distinction between long- and short-term memory. Journal of Verbal Learning and Verbal Behaviour, 9, 176-189.

Bond, M. R. (1975). Assessment of the psycho-social outcome after severe head injury. In Outcome of Severe CNS Damage. CIBA Symposium, November, 1975: London.

Brooks, D. N. (1972). Memory and head injury. Journal of Nervous and Mental Disease, 155, 350-355.

Brooks, D. N. (1974a). Recognition memory and head injury. Journal of Neurology, Neurosurgery, and Psychiatry, 37, 794-780.

Brooks, D. N. (1974b). Recognition memory after head injury: a signal detection analysis. Cortex, 10, 224-230.

Carlsson, C. A., Von Essen, C., and Löfgren, J. (1968). Factors affecting the clinical course of 2 patients with severe head injuries. Journal of Neurosurgery, 29, 242-251.

Denny-Brown, D. (1945). Disability arising from closed head injury. Journal of the American Medical Association, 127, 429-436.

Fahy, T. J., Irving, M. A., and Millac, P. (1967). Severe head injuries. Lancet, 2, 476-479.

Hpay, H. (1971). Psycho-social effects of severe head injury. In Head Injuries. Proceedings of an International Symposium, Edinburgh and Madrid 2-10 March 1970. Churchill Livingstone: Edinburgh.

Kløve, H., and Cleeland, C. S. (1972). The relationship of neuropsychological impairment to other indices of severity of head injury. Scandinavian Journal of Rehabilitation Medicine, 4, 55-60.

Kirk, R. E. (1968). Experimental Design: Procedures for the Behavioral Sciences, pp. 279-281. Brooks/ Cole: Belmont, California.

Levin, H. S., Grossman, R. G., and Kelly, P. J. (1976). Short-term recognition memory in relation to head injury. Cortex. (In press).

Mandleberg, I. A., and Brooks, D. N. (1975). Cognitime recovery after severe head injury. Serial testing on the Wechsler Adult Intelligence Scale. Journal of Neurology, Neurosurgery, and Psychiatry, 38, 1121-1126.

Ruesch, J., and Moore, B. E. (1943). Measurement of intellectual function in the acute stage of head injury. Archives of Neurology and Psychiatry (Chic.) 50, 165-170. 
Russell, W. R. (1971). The Traumatic Amnesias. Oxford University Press: New York.

Talland, G. A. (1965). Deranged Memory. Academic Press: London.

Tooth, G. (1947). On the use of mental tests for the measurement of disability after head injury. Jour- nal of Neurology. Neurosurgery, and Psychiatry, 10, 1-11.

Wechsler, D. (1954). A standardised memory scale for clinical use. Journal of Psychology, 19, 87-95.

Williams, M., and Zangwill, O. L. (1952). Memory defects after head injury. Journal of Neurology, Neurosurgery, and Psychiatry. 15, 54-58. 